\title{
Novel Patterns of Left Ventricular Mechanical Activity During Experimental Cardiac Arrest in Pigs
}

\author{
R. SKULEC ${ }^{1,2,3}$, D. ASTAPENKO ${ }^{1}$, R. CERNA PARIZKOVA ${ }^{1}$, B. FURST ${ }^{4}$, M. BILSKA ${ }^{2}$, \\ T. PARIZEK ${ }^{2}$, T. HOVANEC ${ }^{5}$, N. PINTEROVA ${ }^{6}$, J. KNOR $^{3,7}$, J. DUDAKOVA $^{3}$, \\ A. TRUHLAR ${ }^{1,8}$, V. RADOCHOVA ${ }^{9}$, Z. ZADAK $^{10,11}$, V. CERNY ${ }^{1,2,10,12}$
}

${ }^{1}$ Department of Anesthesiology and Intensive Care, Charles University in Prague, Faculty of Medicine in Hradec Kralove, University Hospital Hradec Kralove, Hradec Kralove, Czech Republic, ${ }^{2}$ Department of Anesthesiology, Perioperative Medicine and Intensive Care, J. E. Purkinje University, Masaryk Hospital Usti nad Labem, Usti nad Labem, Czech Republic, ${ }^{3}$ Emergency Medical Service of the Central Bohemian Region, Kladno, Czech Republic, ${ }^{4}$ Department of Anesthesiology, Albany Medical College, NY, USA, ${ }^{5}$ Faculty of Medicine in Hradec Kralove, Charles University in Prague, Hradec Kralove, Czech Republic, ${ }^{6}$ Faculty of Science, Charles University in Prague, Prague, Czech Republic, ${ }^{7}$ Third Medical Faculty, Charles University in Prague, Prague, Czech republic, ${ }^{8}$ Hradec Kralove Region Emergency Medical Services, Hradec Kralove, Czech Republic, ${ }^{9}$ Faculty of Military Health Sciences, University of Defence, Brno, Czech Republic, ${ }^{10}$ Department of Research and Development, Charles University in Prague, Faculty of Medicine in Hradec Kralove, University Hospital Hradec Kralove, Hradec Kralove, Czech Republic, ${ }^{11}$ Third Department of Internal Medicine - Metabolic Care and Gerontology, Charles University in Prague, Faculty of Medicine in Hradec Kralove, University Hospital Hradec Kralove, Hradec Kralove, Czech Republic, ${ }^{12}$ Department of Anesthesia, Pain Management and Perioperative Medicine, Dalhousie University, Halifax, Nova Scotia, Canada

Received July 20, 2017

Accepted December 1, 2017

On-line March 12, 2018

\section{Summary}

We conducted an experimental study to evaluate the presence of coordinated left ventricular mechanical myocardial activity (LVMA) in two types of experimentally induced cardiac arrest: ventricular fibrillation (VF) and pulseless electrical activity (PEA). Twenty anesthetized domestic pigs were randomized 1:1 either to induction of VF or PEA. They were left in nonresuscitated cardiac arrest until the cessation of LVMA and microcirculation. Surface ECG, presence of LVMA by transthoracic echocardiography and sublingual microcirculation were recorded. One minute after induction of cardiac arrest, LVMA was identified in all experimental animals. In the PEA group, rate of LVMA was of $106 \pm 12 / \mathrm{min}$. In the VF group, we identified two patterns of LVMA. Six animals exhibited contractions of high frequency $\left(V_{\text {high }}\right.$ group), four of low frequency ( $V F_{\text {low }}$ group) (334 \pm 12 vs. $125 \pm 32 /$ min, $p<0.001)$. A time from cardiac arrest induction to asystole (19.2 \pm 7.2 vs. $7.3 \pm 2.2$ vs. $8.3 \pm 5.5 \mathrm{~min}, \mathrm{p}=0.003)$, cessation of LVMA ( $11.3 \pm 5.6$ vs. $4.4 \pm 0.4$ vs. $7.4 \pm 2.9 \mathrm{~min}$, $\mathrm{p}=0.027)$ and cessation of microcirculation ( $25.3 \pm 12.6$ vs. $13.4 \pm 2.4$ vs. $23.2 \pm 8.7 \mathrm{~min}, \mathrm{p}=0.050$ ) was significantly longer in $\mathrm{VF}_{\text {low }}$ group than in $\mathrm{VF}_{\text {high }}$ and PEA group, respectively. Thus, LVMA is present in both VF and PEA type of induced cardiac arrest and moreover, VF may exhibit various patterns of LVMA.

\section{Key words}

Experimental cardiac arrest $\bullet$ Left ventricular Mechanical activity

\section{Corresponding author}

R. Skulec, Department of Anesthesiology, Perioperative Medicine and Intensive Care, Masaryk Hospital Usti nad Labem, Socialni pece 3316/12A, Usti nad Labem 401 13, Czech Republic. Fax: +420 477115 020. E-mail: skulec@email.cz 


\section{Introduction}

Implementation of point-of-care echocardiography in clinical and experimental resuscitation medicine has brought new knowledge about the cardiac arrest (Soar et al. 2015). It has been documented that the clinical syndrome of cardiac arrest is not always accompanied by the presence of mechanical cardiac standstill (Bocka et al. 1988, Breitkreutz et al. 2010). Conversely, in most cases of pulseless electrical activity (PEA) and in some patients presenting with asystole, a preserved coordinated left ventricular mechanical myocardial activity (LVMA) can be observed (Breitkreutz et al. 2010, Cohn et al. 2013). It has been shown that the presence or absence of LVMA exhibits a strong predictive prognostic value for achieving return of spontaneous circulation (ROSC) (Blyth et al. 2012, Blaivas et al. 2001). The absence of LVMA during cardiopulmonary resuscitation (CPR) of patients with non-shockable rhythm indicates a significantly reduced chance of ROSC and vice versa. Intra-arrest ultrasonographic examination may help in the decision-making process regarding the termination of cardiopulmonary resuscitation. In addition to confirming its absence, the presence of LVMA can reinforce enthusiasm of the rescuers to continue providing high-quality CPR. However, many questions remain unanswered, such as the presence of the pathophysiological mechanism of LVMA in patients presenting with asystole. It is further unknown whether myocardial viability depends on the presence of residual cardiac output resulting from LVMA, or on autonomous blood movement at the level of the microcirculation as observed in our previous study and documented in several reports (Thompson 1948, Manteuffel-Szoege et al. 1966, Furst 2014). Finally, it is also necessary to identify whether the phenomenon of LVMA is related only to non-shockable rhythms, or may also occur in cardiac arrest induced by ventricular fibrillation (VF).

We conducted an experimental study to evaluate the presence of coordinated LVMA in two types of experimentally induced cardiac arrest: VF and PEA. We hypothesized that LVMA will be detected in the majority of animals with induced PEA and VF and that its presence will be associated with a longer time to asystole than in animals without LVMA.

\section{Methods}

We performed a prospective randomized controlled experimental study on 20 healthy female domestic experimental pigs (Sus scrofaf. domestica) with weight of $33 \pm 2 \mathrm{~kg}$. The experiment was carried out at the Animal Research Laboratory of the University of Defense, Faculty of Military Health Sciences. The study protocol was approved by the Animal Investigation Committee of the University of Defense Brno, Faculty of Military Health Sciences Hradec Kralove, Czech Republic and the Departmental Commission for the Protection of Animals of the Ministry of Defense, Prague, Czech Republic (approved 14.3.2015, No. 010-2015). All experimental animals received humane care in compliance with the institutional guidelines and with the International Association of Veterinary Editors' Consensus Author Guidelines on Animal Ethics and Welfare.

\section{Animal preparation}

The animals were premedicated by intramuscular injection of azaperone $(2 \mathrm{mg} / \mathrm{kg})$, atropine $(0.2 \mathrm{mg} / \mathrm{kg})$ and ketamine $(20 \mathrm{mg} / \mathrm{kg}) 30 \mathrm{~min}$ before surgery. After the animals were brought into the operating room, peripheral intravenous access was secured and in a supine position, animals were intubated and mechanically ventilated 19 breaths $/ \mathrm{min}, \mathrm{FiO}_{2}$ of 0.4 . Tidal volumes were adjusted to maintain end tidal $\mathrm{CO}_{2}$ of $35-45 \mathrm{~mm} \mathrm{Hg}$. Anesthesia was maintained with a continuous infusion of fentanyl $(5-20 \mu \mathrm{g} / \mathrm{kg} / \mathrm{h})$ and isoflurane inhalation and all animals were given a continuous infusion of normal saline at room temperature $(50 \mathrm{ml} / \mathrm{h})$. Vital signs including ECG were continuously monitored. The thoracic aorta was cannulated via the carotid artery with a 7F $200 \mathrm{~mm}$ catheter Certofix Duo (B. Braun Melsungen AG, Melsungen, Germany) for monitoring of the aortic blood pressure. An 8.5F percutaneous sheath introducer (Intro-Flex, Edwards Lifesciences LLC, Irvine, CA, USA) was inserted via the internal jugular vein into the superior vena cava to facilitate insertion of the bipolar pacing lead and continual monitoring of right atrial pressure. A 5-mm diameter burr-hole craniotomy at the upper part of the frontal bone was created on the left side to insert an intracranial pressure-monitoring probe $20 \mathrm{~mm}$ into the frontal lobe (Codman, Johnson \& Johnson, Raynham, MA, USA). Coronary perfusion pressure (CoPP) was calculated as the pressure difference between diastolic aortic pressure and right atrial pressure 
during the decompression phase. Continuous echocardiographic monitoring was performed by Vivid $i$ ultrasound device (GE Healthcare, Little Chalfont, United Kingdom).

Left ventricular end-diastolic dimension (LVEDD, mm), left ventricular end-systolic dimension (LVESD, mm), interventricular septal thickness at enddiastole (IVSd, $\mathrm{mm}$ ) and posterior wall thickness at enddiastole $(\mathrm{PWd}, \mathrm{mm})$ were recorded every minute and fractional shortening (FS, \%) was calculated following the formula:

$$
F S=((L V E D D-L V E S D) / L V E D D) \cdot 100 .
$$

LVMA was defined as the presence of visible thickening of the interventricular septum and/or left ventricular posterior wall, calculated as $\mathrm{FS}>0 \%$ and related to opening of the valve.

\section{Experimental protocol}

After animal preparation and stabilization, 20 pigs were randomly assigned by envelope method into two groups to induce either ventricular fibrillation (VF group, 10 animals) or pulseless electrical activity (PEA group, 10 animals). Ventricular fibrillation (VF) was induced with an alternating current of $5-10 \mathrm{~V}$ using intra-cardiac bipolar pacing lead introduced into the right ventricle. Pulseless electrical activity (PEA) was initiated by intravenous administration of T61 agent. Cardiac arrest was confirmed as the time point at which both the carotid and femoral pulse was no longer palpable. The animals were left in the state of non-resuscitated cardiac arrest until the cessation of LVMA and sublingual microcirculation. During this period, the animals were monitored for all variables. Thereafter, the animals were autopsied.

Sublingual microcirculation was recorded in each animal by Sidestream dark-field imaging video camera (MicroVision Medical, Amsterdam, Netherlands). All records at baseline were analysed off-line by specialized software AVA 3.0 (MicroVision Medical, Amsterdam, Netherland) and selected parameters of the microcirculation were evaluated, namely, perfused vessel density (PVD) and microvascular flow index (MFI). After initiation of cardiac arrest, the microcirculation was monitored continuously by an experienced observer. Microcirculatory arrest was defined as cessation of red blood cell movement in the visual field.
Major outcomes were the time from cardiac arrest induction to asystole, the time from cardiac arrest induction to cessation of LVMA and the time from cardiac arrest induction to cessation of sublingual microcirculation.

\section{Statistical analysis}

For the statistical analysis, measurements were taken at the baseline and each minute until the end of the experimental protocol. Mean values $\pm \mathrm{SD}$ or percentages were calculated as necessary. Differences between groups were compared using the $\chi^{2}$ test, and statistical significance was calculated by the Fischer exact test for alternative variables. Statistical significance for continuous variables was determined by the paired Student $\mathrm{t}$ test. Data were analysed using Microsoft Excel 2010 (Microsoft, Redmond, WA, USA) and JMP 3.2 statistical software (SAS Institute, Cary, NC, USA). A $p<0.05$ was considered statistically significant.

\section{Results}

The protocol was completed in all experimental animals. One minute after induction of cardiac arrest, LVMA was identified in all experimental animals. In the PEA group, it was tightly coupled with the frequency of QRS complexes on the surface ECG with the heart rate of $106 \pm 12 / \mathrm{min}$. In the VF group, we identified two different patterns of LVMA, regardless of the uniform origin of VF. Six animals exhibited mechanical contractions of high frequency (subsequently assigned as $\mathrm{VF}_{\text {high }}$ group) and four developed low frequency contractions (subsequently assigned as $\mathrm{VF}_{\text {low }}$ group) (334 \pm 12 vs. $125 \pm 32 / \mathrm{min}, \mathrm{p}<0.001)$. Therefore, we compared three groups in further analysis.

During untreated cardiac arrest, asystole developed in all experimental animals before protocol termination, first in $\mathrm{VF}_{\text {high }}$ group, followed by PEA and $\mathrm{VF}_{\text {low }}$ groups (Fig. 1). The time to cessation of LVMA was shortest in $\mathrm{VF}_{\text {high }}$ group, followed by PEA and $\mathrm{VF}_{\text {low }}$ groups, respectively (Fig. 2).

Analysis of the sublingual microcirculation showed normal and comparable values in experimental groups at the baseline for PVD $\left(24.1 \pm 1.1 \mathrm{~mm} / \mathrm{mm}^{2}\right)$ and MFI score (2.9 \pm 0.1$)$.

The time from induction of cardiac arrest to the cessation of microcirculatory flow was shortest in the group $\mathrm{VF}_{\text {high }}$, and in comparison, significantly prolonged in the PEA and $\mathrm{VF}_{\text {low }}$ groups (Fig. 3). 
Table 1 shows the values of hemodynamic parameters and left ventricular fraction shortening. In the PEA group, we observed significantly higher maximal values of pulse pressure (PP), CoPP and FS as defined in the study protocol, and higher values of PP, CoPP and FS in the first three minutes after the induction of cardiac arrest. Maximal post-arrest values of PP and CoPP were observed in the PEA group significantly later than in the $\mathrm{VF}_{\text {high }}$ and $\mathrm{VF}_{\text {low }}$ groups. There were no significant differences in the DAP values among the groups during the protocol. However, significant differences in FS during the first three minutes and at the maximal value were identified between $\mathrm{VF}_{\text {high }}$ and $\mathrm{VF}_{\text {low }}$ groups.

Table 1. PP, DAP, CoPP and FS values during the protocol and comparison among the groups in different time points.

\begin{tabular}{|c|c|c|c|c|c|c|c|}
\hline & & Baseline & 1. $\min$ & 2. $\min$ & 3. $\min$ & maximal & $\operatorname{Tmax}$ \\
\hline \multirow{3}{*}{$\begin{array}{l}P P \\
(m m H g)\end{array}$} & PEA group & $45.3 \pm 13.5$ & $7.8 \pm 2.6^{*}$ & $14.0 \pm 8.7 *$ & $10.8 \pm 6.6^{*}$ & $15.8 \pm 5.0 *$ & $2.9 \pm 0.6^{*}$ \\
\hline & VFlow group & $46.2 \pm 12.2$ & $4.3 \pm 1.0$ & $4.1 \pm 3.1$ & $5.0 \pm 5.4$ & $7.1 \pm 5.0$ & $2.2 \pm 0.6$ \\
\hline & VFhigh group & $47.0 \pm 13.9$ & $4.5 \pm 3.1$ & $3.2 \pm 1.2$ & $1.5 \pm 3.7$ & $5.2 \pm 3.8$ & $1.7 \pm 1.0$ \\
\hline \multirow{3}{*}{$\begin{array}{l}D A P \\
(m m H g)\end{array}$} & PEA group & $62.3 \pm 8.6$ & $19.6 \pm 4.5$ & $20.5 \pm 6.8$ & $19.6 \pm 7.9$ & $22.5 \pm 5.6$ & $2.4 \pm 0.8$ \\
\hline & VFlow group & $62.7 \pm 13.4$ & $17.3 \pm 3.0$ & $16.5 \pm 4.0$ & $16.7 \pm 3.7$ & $18.8 \pm 2.6$ & $2.0 \pm 0.6$ \\
\hline & VFhigh group & $64.2 \pm 7.5$ & $17.7 \pm 2.9$ & $16.5 \pm 0.7$ & $15.7 \pm 0.5$ & $18.5 \pm 1.9$ & $2.0 \pm 1.4$ \\
\hline \multirow{3}{*}{$\begin{array}{l}\text { CoPP } \\
(m m ~ H g)\end{array}$} & PEA group & $55.4 \pm 8.5$ & $8.6 \pm 4.1^{*}$ & $8.2 \pm 7.0 *$ & $6.9 \pm 8.6$ & $10.8 \pm 6.5^{*}$ & $2.6 \pm 0.8^{*}$ \\
\hline & VFlow group & $56.8 \pm 14.8$ & $2.8 \pm 1.2$ & $1.3 \pm 2.4$ & $2.5 \pm 2.9$ & $4.0 \pm 2.3$ & $1.7 \pm 0.8$ \\
\hline & VFhigh group & $57.7 \pm 5.8$ & $2.7 \pm 1.7$ & $2.2 \pm 2.7$ & $1.5 \pm 2.4$ & $3.5 \pm 1.7$ & $1.5 \pm 0.6$ \\
\hline \multirow{3}{*}{$F S(\%)$} & PEA group & $49.2 \pm 6.0$ & $30.9 \pm 11.4 *$ & $44.1 \pm 21.4^{*}$ & $35.3 \pm 19.7^{*}$ & $41.9 \pm 12.2 *$ & $2.1 \pm 0.8$ \\
\hline & VFlow group & $51.2 \pm 6.2$ & $14.9 \pm 8.8^{\bullet}$ & $11.4 \pm 4.7^{\bullet}$ & $9.8 \pm 6.4^{\bullet}$ & $15.5 \pm 8.3^{\bullet}$ & $1.3 \pm 0.5$ \\
\hline & VFhigh group & $52.1 \pm 1.4$ & $4.4 \pm 3.5$ & $5.8 \pm 2.4$ & $2.7 \pm 0.9$ & $7.0 \pm 2.9$ & $1.7 \pm 0.5$ \\
\hline
\end{tabular}

$\mathrm{PP}$ - pulse pressure, DAP - diastolic arterial pressure, CoPP - coronary perfusion pressure, Tmax - time from cardiac arrest induction to the maximal value during the protocol. * indicates $p<0.05$ between $\mathrm{PEA}$ group and $\mathrm{VF}_{\text {high }}$ and $\mathrm{VF}_{\text {low }}$ groups, ${ }^{\bullet}$ indicates $p<0.05$ between $\mathrm{VF}_{\text {high }}$ group and $\mathrm{VF}_{\text {low }}$ group.

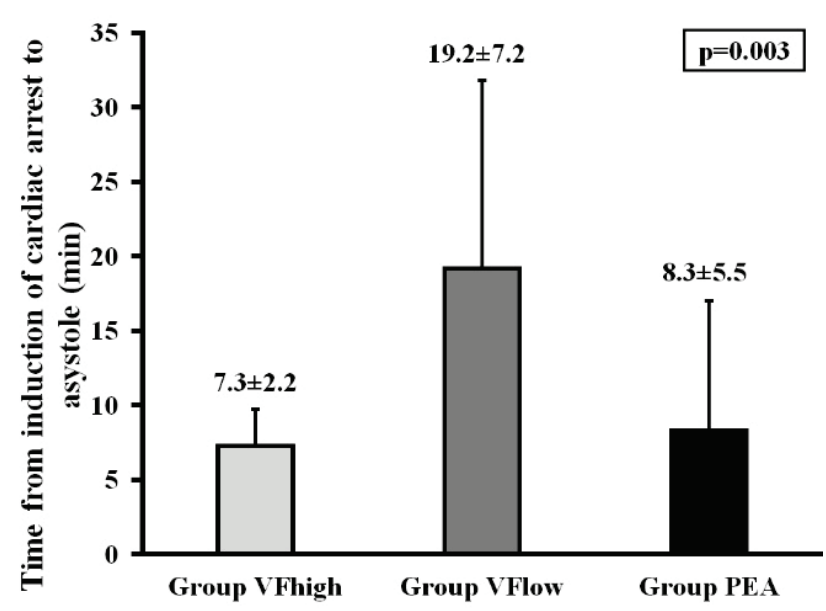

Fig. 1. Time from induction of cardiac arrest to development of asystole in experimental groups.

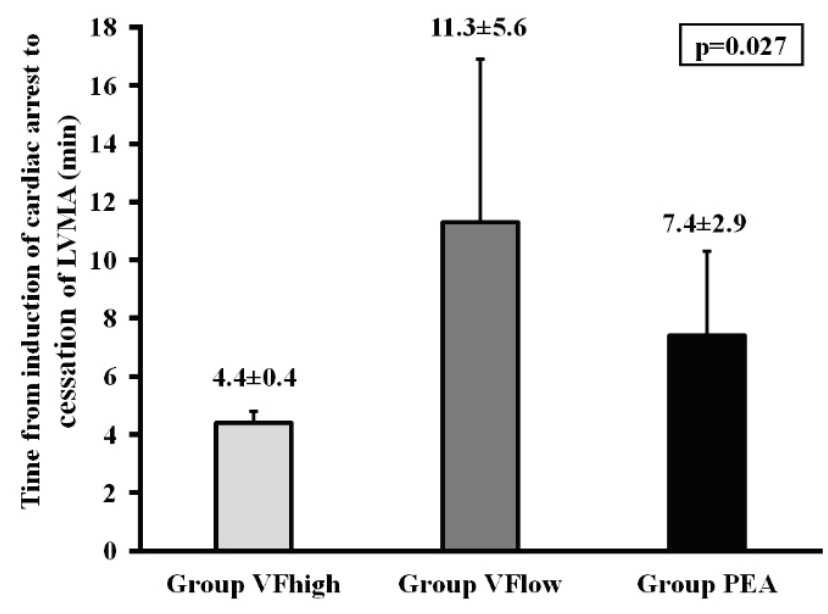

Fig. 2. Time from induction of cardiac arrest to cessation of LVMA in experimental groups. LVMA - Left ventricular mechanical activity. 


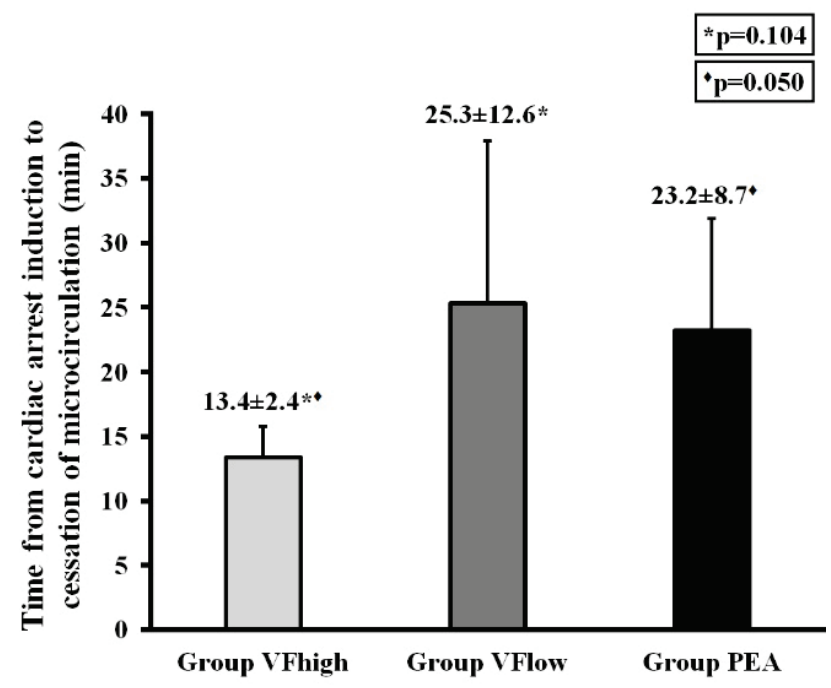

Fig. 3. Time from induction of cardiac arrest to cessation of microcirculation.

\section{Discussion}

The main findings of the present study are that LVMA was found to be preserved for a certain period after induction of $\mathrm{CA}$ in all experimental animals regardless of the induced electrical activity, two patterns of LVMA were identified in VF group animals and the pattern with LVMA of low frequency contractions $\left(\mathrm{VF}_{\text {low }}\right.$ group) was associated with the longest time from CA induction to asystole to cessation of LVMA and microcirculation among the groups.

It has been known for some time that the clinical syndrome of cardiac arrest is not always accompanied by a mechanical cardiac standstill. Bocka et al. (1998) performed echocardiography in a group of patients presenting with electromechanical dissociation and demonstrated synchronous myocardial wall motion in 19 out of 22 patients. Paradise et al. (1992) measured aortic pressure in 94 patients with PEA and found that 39 have measurable pulse pressure $(6.3 \pm 3.5 \mathrm{~mm} \mathrm{Hg})$. The phenomenon of preserved LVMA in patients presenting with PEA is known as pseudo-PEA. Studies have confirmed that pseudo-PEA is a common finding occurring in $58 \%$ of patients with out-of-hospital, and in up to $55 \%$ of patients with in-hospital cardiac arrest (Breitkreutz et al. 2010, Flato et al. 2015). Moreover, LVMA has been identified in up to $35 \%$ cardiac arrest patients with asystole (Breitkreutz et al. 2010). Blyth et al. (2012) performed a meta-analysis of 12 clinical studies and showed that intra-arrest echocardiography had sensitivity of $91.6 \%$ and specificity of $80 \%$ as predictors of ROSC. The absence of LMVA predicts a very low likelihood of ROSC and vice versa.

The observed phenomenon of the presence of LVMA in all animals of the PEA group is consistent with clinical studies published previously (Breitkreutz et al. 2010, Flato et al. 2015).

Surprisingly, we observed the occurrence of LVMA also in animals with induced VF. Unlike in the case of PEA, there has been no published observations of coordinated LVMA in VF. Moreover, we identified two patterns of LVMA. In six animals, subsequently assigned to $\mathrm{VF}_{\text {high }}$ group, LVMA was present at the limit of measurability and at the rate of anticipated frequency of ventricular fibrillation. LVMA at low frequency was observed in four experimental animals. We now discuss the possible pathophysiological sequence of events in the VF groups.

In spite of voluminous literature on the causes of electrical myocardial activity during $\mathrm{VF}$, the nature of its origin, maintenance and hemodynamic impact are not understood. Several experimental and clinical observations support the hypothesis of an "organization pattern" in persistent VF. Wiggers et al. (2003) identified in electrically stimulated canine hearts 4 phases in the genesis of VF. At the onset, a well-organized type of arrhythmia was observed consisting of one or two rotors with re-entrant electrical activity, called the mother-rotor. This was followed by less-well organized wavefronts, which may constitute the basis for further rotors (Wiggers et al. 2003). This activity was further defined by Huang et al. (2004) who quantitated the VF and showed that its organization does not invariably decrease, but can fluctuate. A controversy continues over the issue whether the dominant cause of VF is a single re-entrant motherrotor, or the genesis of newly emerging, wandering wavelets. Experimental findings shows that, depending on the experimental model, duration and stage of VF and drug therapy, both mechanisms can be present (Chen et al. 2003, Tabereaux et al. 2009, Fenton et al. 2002, Huang et al. 1998, Bourgeois et al. 2012, Rogers et al. 2007, Li et al. 2008, Pak et al. 2006, Cheng et al. 2012, Nielsen et al. 2009, Lin et al. 2014). The heterogeneity in VF maintenance and the complexity of its electrical activity confirms the importance of visual assessment of LVMA by means of point-of-care ultrasonography.

Another potential mechanism that may explain our observation of different LVMA rate in $\mathrm{VF}_{\text {high }}$ and $\mathrm{VF}_{\text {low }}$ groups is based on the possible role of atrial activity on mechanical left ventricular performance 
during VF. In spite of the fact that atrial activity cannot be assessed from the surface ECG during VF, effective atrial ejection can be present (Addison et al. 2002). In our experiments, VF was induced in healthy animals with normal sinus rhythm without structural myocardial abnormality. In such experimental setting, the loss of sinus rhythm after VF induction requires the presence of retrograde conduction. However, this is not an ubiquitous feature of the conduction system in humans and experimental animals (Molina et al. 1989, Goldreyer et al. 1970, Bowman et al. 1984, Pickoff et al. 1984). It is possible that the pattern of ongoing, sustained VF presenting with fully organized atrial activity, i.e. atrial systole, may have been present in some of our experimental animals, giving rise to pulsatile volumeloading of the left ventricle and directly, or indirectly inducing the echocardiographic phenomenon of low-frequency LVMA.

It is also possible that in $\mathrm{VF}_{\text {low }}$ group, the effective atrial activity was preserved and LVMA phenomenon was predominantly a passive process. In the $\mathrm{VF}_{\text {high }}$ group, on the other hand, the LVMA may reflect high frequency contractions with minimal FS directly related to VF activity.

It is questionable, however, whether the presence of LVMA characterizes even a minimal degree of effective cardiac output. What is essential is that various modes of LVMA during VF can be related to different electrical patterns of $\mathrm{VF}$ maintenance and thus to myocardial viability and resistance to ischemia. We hypothesize that these factors could influence not only defibrillation thresholds but also the time window for efficient defibrillation.

It is noteworthy that in the early phase of induced cardiac arrest, LVMA was observed in all experimental animals. This suggests that LVMA is a regular occurrence in the early phases of VF and PEA and supports the idea that cardiac arrest is not a static condition but a dynamic process which, left untreated, inevitable leads to irreversible cardiac standstill.

Finally, we observed flow of blood at the level of the microcirculation well beyond the timing of the cardiac arrest in all 3 experimental groups (Fig. 3). The phenomenon of circulation persisting at the organ and tissue level after the recordable LVMA supports the concept that blood possesses its own kinetic energy determined by the metabolic demands of the tissues and calls for a revision of the conventional, pressurepropulsion circulation model (Furst 2015, Alexander
2017, Forouhar et al. 2006). Intravital microscopy of early embryonic circulations has confirmed that a low-pressure circulation already exists before the functional integrity of the heart (Forouhar et al. 2006). It has further been shown that the valveless embryo heart functions as an impedance pump which rhythmically interrupts the already existing flow of blood (Furst 2014). Irrespective of structural differences, the function of the mature heart is essentially the same as that of the embryonic heart. In addition to rhythmic interruption of the flow, the ventricles eject the blood into the pulmonary/systemic arterial compartments at higher pressures. Thus, above the blood's primary streaming at the level of the microcirculation, which is subject to local control, i.e. organ and tissue autoregulation, the secondary, or macrocirculatory flow is subject to complex control at the systemic level. According to the ontogenic circulation model, the syndrome of cardiac arrest primarily manifests as the collapse of arterial pressure due to the heart's inability to rhythmically interrupt the flow of blood. Even though the resuscitation efforts are primarily directed at restoring a rhythm that will sustain the macrocirculation, experimental CPR protocols which in addition enhance the microcirculatory flow have shown favorable outcomes (Yannopoulos et al. 2012). The proposed circulation model is moreover consistent with recent advances in the understanding of critical illness. Collectively, they demonstrate uncoupling or incoherence between observed microvascular parameters, such as functional capillary density and red blood cell velocity, and routinely measured macrovascular parameters, such as arterial blood pressure, cardiac output, ejection fraction, and mixed venous oxygen saturation (Ince 2015). The loss of hemodynamic coherence has thus been identified as the common denominator of various states of shock. Left uncorrected, such incongruence inevitably leads to a complete dissociation between the two circulatory components and to cardiac arrest. The phenomenon of persistenting microcirculation after cardiac arrest thus offers a new insight into the pathogenesis and possible treatment of this insidious condition.

There are a few study limitations. Firstly, this is an experimental study and the results should be interpreted with caution when related to clinical medicine. Cardiac arrest was induced in healthy young animals, without any myocardial or pulmonary disease. Since we did not directly measure the intracardiac pressures and ECG's, only a hypothetical explanation 
regarding electrical events and intracardiac blood flows can be given. Secondly, with regard to LVMA patterns, we can not completely rule out effect of anesthetics agents on the obtained results in experimental groups. Several authors show that inhaled and intravenous anesthetic may have differential, direct or indirect, effect on myocardial functions (Süzer et al. 1998, De Hert 1991, Stowe et al. 1992) Addition of fentanyl and sevoflurane was associated with inhibiting ventricular fibrillation in one clinical report (Yamagishi et al. 2003). On the other hand, the same type of anesthesia was used in all experimental animals in comparable doses.

In conclusion, we observed that LVMA was found to be preserved for a certain period of induced cardiac arrest in all animals in our experiment. In the VF group, two patterns of LVMA were identified, one with low and one with very high frequency. We hypothesize the underlying mechanism of different LVMA pattern in animals with induced VF. Anyhow, presentation of LVMA with low frequency contractions was associated with increased resistance to cessation of LVMA and microcirculation. We also observed the persistence of microcirculatory blood flow after cardiac standstill. This phenomenon supports the concept that blood possesses its own kinetic energy determined by the metabolic demands of the tissues and support a revision of the conventional circulation model. Further research is needed to explain the pathophysiological explanation of our observations and potential consequences for clinical medicine.

\section{Conflict of Interest}

There is no conflict of interest.

\section{Acknowledgements}

Supported by the program PROGRES Q40/2 and by MH CZ - DRO (UHHK, 00179906).

\section{References}

ADDISON PS, WATSON JN, CLEGG GR, STEEN PA, ROBERTSON CE: Finding coordinated atrial activity during ventricular fibrillation using wavelet decomposition. IEEE Eng Med Biol Mag 21: 58-61, 2002.

ALEXANDER W: Branko Furst's radical alternative: Is the heart moved by the blood, rather than vice versa? Pharmacol Ther 42: 33-39, 2017.

BLAIVAS M, FOX JC: Outcome in cardiac arrest patients found to have cardiac standstill on the bedside emergency department echocardiogram. Acad Emerg Med 8: 616-621, 2001.

BLYTH L, ATKINSON P, GADD K, LANG E: Bedside focused echocardiography as predictor of survival in cardiac arrest patients: a systematic review. Acad Emerg Med 19: 1119-1126, 2012.

BOCKA JJ, OVERTON DT, HAUSER A: Electromechanical dissociation in human beings: an echocardiographic evaluation. Ann Emerg Med 17: 450-452, 1988.

BOWMAN TA, HUGHES HC: Ventriculoatrial conduction in swine during cardiac pacing: animal model for retrograde conduction. Am Heart J 108: 337-341, 1984.

BREITKREUTZ R, PRICE S, STEIGER HV, SEEGER FH, ILPER H, ACKERMANN H, RUDOLPH M, UDDIN S, WEIGAND MA, MÜLLER E, WALCHER F: Emergency Ultrasound Working Group of the Johann Wolfgang Goethe-University Hospital, Frankfurt am Main: Focused echocardiographic evaluation in life support and peri-resuscitation of emergency patients: A prospective trial. Resuscitation 81: 1527-1533, 2010.

BOURGEOIS EB, REEVES HD, WALCOTT GP, ROGERS JM: Panoramic optical mapping shows wavebreak at a consistent anatomical site at the onset of ventricular fibrillation. Cardiovasc Res 93: 272-279, 2012.

CHEN PS, WU TJ, TING CT, KARAGUEUZIAN HS, GARFINKEL A, LIN SF, WEISS JN: A Tale of two fibrillations. Circulation 108: 2298-2303, 2003.

CHENG KA, DOSDALL DJ, LI L, ROGERS JM, IDEKER RE, HUANG J: Evolution of activation patterns during long-duration ventricular fibrillation in pigs. Am J Physiol Heart Circ Physiol 302: H992-H1002, 2012.

COHN B: Does the absence of cardiac activity on ultrasonography predict failed resuscitation in cardiac arrest? Ann Emerg Med 62: 180-181, 2013.

DE HERT SG: Study on the effects of six intravenous anesthetic agents on regional ventricular function in dogs (thiopental, etomidate, propofol, fentanyl, sufentanil, alfentanil). Acta Anaesthesiol Belg 42: 3-39, 1991. 
FENTON FH, CHERRY EM, HASTINGS HM, EVANS SJ: Multiple mechanisms of spiral wave breakup in a model of cardiac electrical activity. Chaos 12: 852-892, 2002.

FLATO UAP, PAIVA EF, CARBALLO MT, BUEHLER AM, MARCO R, TIMERMAN A: Echocardiography for prognostication during the resuscitation of intensive care unit patients with non-shockable rhythm cardiac arrest. Resuscitation 92: 1-6, 2015.

FOROUHAR AS, LIEBLING M, HICKERSON A, NASIRAEI-MOGHADDAM A, TSAI HJ, HOVE JR, FRASER SE, DICKINSON ME, GHARIB M: The embryonic vertebrate heart tube is a dynamic suction pump. Science 312: 751-753, 2006.

FURST B: The heart: pressure-propulsion pump or organ of impedance? J Cardiothorac Vasc Anesth 29: 1688-1701, 2015.

FURST B: The Heart and Circulation - An Integrative Model. Springer-Verlag, London, 2014, 226 p.

GOLDREYER BN, BIGGER JT JR: Ventriculo-atrial conduction in man. Circulation 41: 935-946, 1970.

HUANG J, ROGERS JM, KILLINGSWORTH CR, SINGH KP, SMITH WM, IDEKER RE: Evolution of activation patterns during long-duration ventricular fibrillation in dogs. Am J Physiol Heart Circ Physiol 286: H1193-H1200, 2004.

HUANG J, ROGERS JM, KENKNIGHT BH, ROLLINS DL, SMITH WM, IDEKER RE: Evolution of the organization of epicardial activation patterns during ventricular fibrillation. $J$ Cardiovasc Electrophysiol 9: 1291-1304, 1998.

INCE C: Hemodynamic coherence and the rationale for monitoring the microcirculation. Crit Care 19 (Suppl 3): S8, 2015.

LI L, JIN Q, HUANG J, CHENG KA, IDEKER RE: Intramural foci during long duration fibrillation in the pig ventricle. Circ Res 102: 1256-1264, 2008.

LIN C, JIN Q, ZHANG N, ZHOU J, PANG Y, XIN Y, LIU S, WU Q, WU L: Endocardial focal activation originating from Purkinje fibers plays a role in the maintenance of long duration ventricular fibrillation. Croat Med J 55: 121-127, 2014.

MANTEUFFEL-SZOEGE L, MICHALOWSKI J, GRUNDMAN J, PACOCHA W: On the possibility of blood circulation continuing after stopping the heart. J Cardiovasc Surg (Torino) 7: 201-208, 1966.

MOLINA RZ, FUJIMURA O, SHARMA AD, YEE R, KLEIN GJ: Atrioventricular nodal tachycardia in the absence of retrograde conduction. Can J Cardiol 5: 143-146, 1989.

NIELSEN TD, HUANG J, ROGERS JM, KILLINGSWORTH CR, IDEKER RE: Epicardial mapping of ventricular fibrillation over the posterior descending artery and left posterior papillary muscle of the swine heart. $J$ Interv Card Electrophysiol 24: 11-17, 2009.

PAK HN, KIM YH, LIM HE, CHOU CC, MIYAUCHI Y, FANG YH, SUN K, HWANG C, CHEN PS: Role of the posterior papillary muscle and purkinje potentials in the mechanism of ventricular fibrillation in open chest dogs and swine: effects of catheter ablation. J Cardiovasc Electrophysiol 17: 777-783, 2006.

PARADIS NA, MARTIN GB, GOETTING MG, RIVERS EP, FEINGOLD M, NOWAK RM: Aortic pressure during human cardiac arrest. Identification of pseudo-electromechanical dissociation. Chest 101: 123-128, 1992.

PICKOFF AS, SINGH S, FLINN CJ, TORRES E, EZRIN AM, GELBAND H: Maturational changes in ventriculoatrial conduction in the intact canine heart. $J$ Am Coll Cardiol 3: 162-168, 1984.

ROGERS JM, WALCOTT GP, GLADDEN JD, MELNICK SB, KAY MW: Panoramic optical mapping reveals continuous epicardial reentry during ventricular fibrillation in the isolated swine heart. Biophys $J$ 92: 1090-1095, 2007.

SOAR J, NOLAN JP, BÖTTIGER BW, PERKINS GD, LOTT C, CARLI P, PELLIS T, SANDRONI C, SKRIFVARS MB, SMITH GB, SUNDE K, DEAKIN CD: Adult advanced life support section Collaborators: European Resuscitation Council Guidelines for Resuscitation 2015 Section 3. Adult advanced life support. Resuscitation 95: 100-147, 2015.

STOWE DF, BOSNJAK ZJ, KAMPINE JP: Comparison of etomidate, ketamine, midazolam, propofol, and thiopental on function and metabolism of isolated hearts. Anesth Analg 74: 547-558, 1992. 
SÜZER O, SÜZER A, AYKAÇ Z, OZÜNER Z: Direct cardiac effects in isolated perfused rat hearts measured at increasing concentrations of morphine, alfentanil, fentanyl, ketamine, etomidate, thiopentone, midazolam and propofol. Eur J Anaesthesiol 15: 480-485, 1998.

TABEREAUX PB, DOSDALL DJ, IDEKER RE: Mechanisms of VF maintenance: wandering wavelets, mother rotors, or foci. Heart Rhythm 6: 405-415, 2009.

THOMPSON SA: The effect of pulmonary inflation and deflation upon the circulation. J Thorac Surg 17: 323-334, 1948.

WIGGERS CJ, BELL JR, PAINE M: Studies of ventricular fibrillation caused by electric shock: II. Cinematographic and electrocardiographic observations of the natural process in the dog's heart. Its inhibition by potassium and the revival of coordinated beats by calcium. Ann Noninvasive Electrocardiol 8: 252-261, 2003.

YAMAGISHI A, HAMADA I, TAKAHATA O, NAGASHIMA M, FUJIMOTO K, IWASAKI H: Suppression of frequent ventricular fibrillation attacks after induction of anesthesia with fentanyl, sevoflurane and propofol: a case report. Masui 52: 750-752, 2003.

YANNOPOULOS D, SEGAL N, MCKNITE S, AUFDERHEIDE TP, LURIE KG: Controlled pauses at the initiation of sodium nitroprusside-enhanced cardiopulmonary resuscitation facilitate neurological and cardiac recovery after 15 mins of untreated ventricular fibrillation. Crit Care Med 40: 1562-1569, 2012. 